\title{
Studies on the transovarial transmission of Borrelia burgdorferi sensu lato in the taiga tick Ixodes persulcatus
}

\author{
Valentina V. Nefedova, Edward I. Korenberg, Nataliya B. Gorelova and Yury V. Kovalevskii \\ Gamaleya Research Institute for Epidemiology and Microbiology, Russian Academy of Medical Sciences, 18 Gamaleya Street, \\ 123098 Moscow, Russia
}

Key words: Borrelia burgdorferi, Ixodes persulcatus, ticks, transovarial transmission

\begin{abstract}
The possibility of vertical transmission of Borrelia burgdorferi sensu lato in Ixodes persulcatus Schulze, 1930 ticks was studied in the progeny of 20 females collected from the vegetation in an active focus of ixodid tick-borne borrelioses (ITBB) located in the Perm oblast, Russia, where Borrelia garinii and B. afzelii are circulating. The presence of Borrelia DNA was detected by the PCR method after feeding and egg laying in 16 engorged females (80.0\%), as well as in $36.5 \pm 7.2 \%$ samples containing 20 eggs each and in $21.4 \pm 4.2 \%$ samples containing 10 eggs each. The respective rates of individual egg infection were $0.4-8.0 \%$ and $0.5-23.0 \%$. PCR analysis of 370 eggs (one egg per sample) and 781 unfed larvae hatched from the same egg masses $(1,10,20,40$, and 50 larvae per sample) failed to reveal the presence of Borrelia DNA. Negative results were also obtained in experiments on inoculating the BSK II medium with the egg and larval materials. Microscopic analysis of 1,683 smear preparations of eggs and 1,416 preparations of unfed daughter larvae revealed spirochete-like cells in $7(0.4 \pm 0.3 \%)$ and $13(0.9 \pm 0.5 \%)$ preparations, respectively; typical Borrelia cells were found in seven preparations of larvae $(0.5 \pm 0.4 \%)$. Only 1 out of 16 infected females transmitted Borrelia vertically, through the eggs to the larval progeny. The infection rate in this progeny was about $7 \%$, and the prevalence of Borrelia in individual larvae was $0.4-0.8$ cells per 100 microscopic fields. These data do not allow the conclusion that transovarial transmission of B. burgdorferi sensu lato in the I. persulcatus tick is an established fact. However, they show that, even if such transmission is possible, its probability is very low.
\end{abstract}

In the greater part of the forest zone in Eurasia, the taiga tick Ixodes persulcatus Schulze, 1930 is the main epidemiologically significant vector of Borrelia burgdorferi sensu lato. The rate of tick infection by Borrelia is one of the main parameters characterizing the epizootic state of a natural focus and its potential epidemiological hazard. This rate is largely determined by the processes of spirochete transmission between reservoir hosts (horizontal transmission) and between different phases of tick development (transstadial and, probably, transovarial transmission).

According to available data, which are scarce and often insufficiently representative, the frequency of transovarial Borrelia transmission in I. persulcatus ticks may vary from 0 to $100 \%$ (Du Yong et al. 1990, Nakao and Miyamoto 1992, Balashov and Grigor'eva 1997, Balashov et al. 1998, Grigor'eva and Tret'kiakov 1998, Dubinina 2000). They have provided a basis for diverse and, in some cases, incompatible conclusions: some specialists deny the very possibility of transovarial transmission (Nakao and Miyamoto 1992), whereas others assign great significance to this phenomenon (Balashov and Grigor'eva 1997, Balashov et al. 1998, Grigor'eva and Tret'kiakov 1998). Hence, the main purpose of this study was to quantitatively estimate the possibility of vertical transmission of B. burgdorferi sensu lato in spontaneously infected female $I$. persulcatus and the significance of this phenomenon for Borrelia circulation in natural foci.

\section{MATERIALS AND METHODS}

Adult ticks were collected from the vegetation by flagging in the Pre-Ural region of Russia (Tchusovskii district, Perm oblast) in May and June 1999. Long-term observations in this region have shown that Borrelia garinii and B. afzelii circulate there (Korenberg et al. 1999), and the infection rate among unfed adult ticks (estimated by dark-field microscopic analysis) varies in different years from 29.6 to $60.8 \%$ (Korenberg et al. 1999). According to the results of parallel analysis of 125 unfed female ticks by means of dark-field microscopy and PCR (see below), the infection rate in the corresponding biotope at the time of sampling was estimated at $52.0 \%$ by the first method and $64.0 \%$ by the second method.

Male and female I. persulcatus ticks were kept before experiments in separate tubes at $4^{\circ} \mathrm{C}$. Twenty females were allowed to feed individually, in the presence of a male, on outbred white mice. After feeding, they were kept in individual tubes with a humidity gradient. Upon completing egg laying, each female was analysed for Borrelia infection by the PCR method.

On the whole, the females laid 19 egg masses, and the larvae hatched out of 17 egg masses. The eggs and unfed larvae taken from different parts of each egg mass were studied by several methods (Tables 1,2).

Culture method. The pools of 50 eggs or 10 larvae were washed with $70 \%$ ethanol (less than 2 min for the eggs and approximately $5 \mathrm{~min}$ for the larvae), sterile distilled water, and a solution of $0.9 \% \mathrm{NaCl}$ (2 min each) in sterile Petri dishes and were used for inoculating the BSK II medium without 
antibiotics in 2-ml sterile polystyrene tubes filled to threefourth of their capacity. The eggs were either homogenized in $200 \mu \mathrm{l}$ of the medium or simply placed in the tube and punctured with a dissection needle. In the larvae, the gnathosoma was aseptically removed under a microscope, and the body was transferred to the cultivation tube (Gorelova et al. 1996). The tubes were closed with airtight screw caps and incubated at $32^{\circ} \mathrm{C}$ for two months. Every week, the cultures were tested for the presence of Borrelia by analysing test samples under a microscope with a dark-field condenser at a magnification of $600 \times(100$ microscopic fields per culture $)$.

Microscopic analysis of fixed smears. The contents of an egg crushed with a dissecting needle were smeared on a glass slide. The preparations of unfed larvae and the ovaries of unfed females were made as described by Levin et al. (1993). The smears were dried, flame-fixed over an alcohol burner, and stained using the Giemsa stain according to Romanovskii and a solution of $1 \%$ Crystal Violet for $30 \mathrm{~min}$. In each preparation, 250 microscopic fields were examined at a magnification of $600 \times$ to determine the concentration of Borrelia, which was expressed as the number of spirochetes per 100 microscopic fields.

PCR analysis. The biological samples were washed in $70 \%$ ethanol and distilled water, dried on absorbent paper, placed in 1.5-ml Eppendorf tubes, and stored before analysis at $-70^{\circ} \mathrm{C}$. Borrelia genomic DNA was isolated using guanidine thiocyanate treatment and phenol-chloroform extraction according to Gushchin and Khalilov (1996) (see Nefedova et al. 2001). When necessary, DNA samples were stored at $-20^{\circ} \mathrm{C}$. DNA amplification was performed as described by Salinas-Melendez et al. (1995), with some modifications, using the conservative primers BB1 and BB2 flanking a 244bp fragment of the B. burgdorferi 16S rRNA gene (Adam et al. 1990). The reaction mixture $(25 \mu \mathrm{l})$ in $10 \times$ buffer $(67 \mathrm{mM}$ Tris-HCl, pH 8.6; $16.6 \mathrm{mM}\left(\mathrm{NH}_{4}\right)_{2} \mathrm{SO}_{4} ; 2.5 \mathrm{mM} \mathrm{MgCl}{ }_{2}$; $0.001 \%$ Triton X-100; and $0.12 \mathrm{mg} / \mathrm{ml} \mathrm{BSA}$ ) contained the four deoxynucleoside triphosphates (dATP, dCTP, dGTP, and dTTP) at a final concentration of $0.2 \mathrm{mM}, 15$ pmoles of each primer, 1.5 units of Taq polymerase, $10 \mu 1$ of the test DNA sample, and a drop of mineral oil. In the "blank" control, deionized water instead of DNA was added. The procedure of DNA amplification involved five cycles of reaction at 94, 40, and $72^{\circ} \mathrm{C}$ followed by 30 cycles at 94,50 , and $72^{\circ} \mathrm{C}(1 \mathrm{~min}$ at each temperature) in a four-channel TherCyc thermocycler (NPO DNK Tekhnologiya, Russia). To estimate the specificity of amplification, a set of DNA samples from different spirochete species was included in analysis. To this end, we used the isolates of spirochetes of different groups kept at the Museum of Borrelia Cultures of the Vector Laboratory, Gamaleya Research Institute for Epidemiology and Microbiology, Russian Academy of Medical Sciences:

(a) The B. burgdorferi sensu lato group was represented by $B$. afzelii, type strain Ip-21 (derived from an adult $I$. persulcatus tick caught in Leningrad oblast in 1987); $B$. garinii, isolate Ipl-4906 (from an engorged I. persulcatus larva caught in Perm oblast in 2000); B. burgdorferi sensu stricto, strains B 31 ATCC 35210 (isolated from an I. dammini tick in the United States in 1982, kindly supplied by Dr. A. Barbour) and TxGW (isolated from a diseased person in the United States in 1986, kindly supplied by Dr. R. Johnson); and $B$. valaisiana, isolate Ir-4804 (from an I. ricinus tick caught in Krasnodar krai in 2000).

(b) Spirochetes of the group causing tick-borne relapsing fevers included $B$. persica, strain Batyr HT-20 (isolated from Ornithodoros papillipes ticks in Uzbekistan in 1988); $B$. recurrentis (the blood of mice infected with the culture kindly supplied by Prof. J. Chalupský, Czech Republic); and $B$. hermsii, serotype $\mathrm{C}$ (isolated from the blood of a diseased teenager in the United States in 1990, kindly supplied by Dr. A. Barbour).

(c) The Leptospira group was represented by the L. biflexa serovar patoc (I) (from the Museum of the Leptospirosis Laboratory, Gamaleya Research Institute for Epidemiology and Microbiology, Russian Academy of Medical Sciences).

The resulting PCR products were compared by electrophoresis, with the GeneRuler ${ }^{\mathrm{TM}} 100$ bp DNA Ladder marker kit (MBI Fermentas, Lithuania) used for determining DNA length. No reaction with samples containing other spirochetes than B. burgdorferi sensu lato was observed, confirming that PCR amplification of the test samples was $100 \%$ specific. The detection limit of the method was approximately 100 spirochetes per sample. To correctly interprete the results of PCR analysis, we performed additional experiments with the DNA of B. afzelii strain Ip-21 (the positive control) and the DNAs of a female I. ricinus from the laboratory colony of uninfected ticks (Institute of Zoology, Switzerland; kindly supplied by Dr. L. Gern), its eggs, and a larva hatched from the same egg mass (the negative controls). The products of PCR amplification, including the blank control (see above), were compared by means of agarose gel electrophoresis in horizontal slabs in the presence of ethidium bromide $(1-2 \%$ agarose in Trisacetate buffer, $\mathrm{pH} 8.1 ; 165 \mathrm{~V})$. The resulting electrophoretic patterns were analysed using a DNA Analyzer videosystem with the Gel-Imager and Gel-Analysis version 1.0 software programs (Russia). The result of PCR was regarded as positive or negative depending on the presence or absence of an amplification product corresponding to the specific fragment of the control DNA preparation.

\section{RESULTS}

Spirochetes were found in the ovaries of 3 out of 96 unfed females $(3.1 \pm 3.5 \%)$ studied by means of microscopic analysis of fixed smears, and the presence of Borrelia DNA was detected by the PCR method in 16 out of 20 engorged females, which was evidence for the possibility of transovarial pathogen transmission. The females laid a total of 19 egg masses. The DNA of Borrelia was detected in approximately one-fifth of 10egg pools and one-third of 20-egg pools obtained from the engorged females, with the difference in infection rate between the pools being statistically significant (Student's $t$-test, $t=3.6$ ). The data on egg infection obtained by the group suspension method (Table 1) were used for calculating the probable rate of individual egg infection for an egg mass by the formula proposed by Beklemishev $(1963)^{1}$. The rates calculated from data on the pools of 10 and 20 eggs were $0.5-23.0 \%$ and $0.4-8.0 \%$, respectively. However, the results of

${ }^{1} P_{o}=\mathrm{e}^{-M}, M=-\ln P_{o}$, where $P_{o}$ is probable infection rate, e is the base of natural logarithm, and $M$ is the average number of infected ticks (eggs) per batch in the total sample. 
Table 1. Rates of Borrelia infection of eggs laid by infected Ixodes persulcatus ticks as estimated by different methods.

\begin{tabular}{|l|c|c|c|c|c|}
\hline \multirow{2}{*}{ Method } & \multirow{2}{*}{$\begin{array}{c}\text { No. pools / eggs } \\
\text { studied }\end{array}$} & \multicolumn{4}{|c|}{ Samples containing } \\
\cline { 3 - 6 } & & $\begin{array}{c}|c| \\
\text { infected/ } \\
\text { examined }\end{array}$ & $\%\left(\mathrm{P} \pm 2 \mathrm{~m}_{\mathrm{p}}\right)$ & $\begin{array}{c}\text { infected } / \\
\text { examined }\end{array}$ & $\%\left(\mathrm{P} \pm 2 \mathrm{~m}_{\mathrm{p}}\right)$ \\
\hline $\begin{array}{c}\text { Cultivation } \\
\text { (pools of 50 eggs) }\end{array}$ & $12 / 600$ & 0 & 0 & $5 / 12^{1}$ & $41.7 \pm 28.5 /-$ \\
$\begin{array}{c}\text { Microscopy of fixed } \\
\text { smears }\end{array}$ & $-/ 1,683$ & 0 & 0 & $7 / 1,683^{2}$ & $-/ 0.4 \pm 0.3$ \\
$\begin{array}{c}\text { PCR analysis of } \\
\text { individual eggs }\end{array}$ & $-/ 370$ & 0 & 0 & - & - \\
samples of 10 eggs & $378 / 3,780$ & $81 / 378^{1}$ & $21.4 \pm 4.2 /-$ & - & - \\
samples of 20 eggs & $178 / 3,560$ & $65 / 178^{1}$ & $36.5 \pm 7.2 /-$ & - & - \\
\hline
\end{tabular}

${ }^{1}$ examined by pools; ${ }^{2}$ examined individually

Table 2. Rates of Borrelia infection of unfed Ixodes persulcatus larvae as estimated by different methods.

\begin{tabular}{|c|c|c|c|c|c|}
\hline \multirow{2}{*}{ Method } & \multirow{2}{*}{$\begin{array}{c}\text { No. pools / larvae } \\
\text { studied }\end{array}$} & \multicolumn{4}{|c|}{ Samples containing } \\
\cline { 3 - 6 } & & $\begin{array}{c}\text { typical Borrelia } \\
\text { infected/ } \\
\text { examined }\end{array}$ & $\%\left(\mathrm{P} \pm 2 \mathrm{~m}_{\mathrm{p}}\right)$ & $\begin{array}{c}\text { sinfected/ } \\
\text { examined }\end{array}$ & $\%\left(\mathrm{P} \pm 2 \mathrm{~m}_{\mathrm{p}}\right)$ \\
\hline $\begin{array}{c}\text { Cultivation (pools } \\
\text { of 10 larvae) }\end{array}$ & $60 / 600$ & 0 & 0 & $16 / 60^{1}$ & $26.7 \pm 11.4 /-$ \\
\hline $\begin{array}{c}\text { Microscopy of } \\
\text { fixed smears }\end{array}$ & $-/ 1,416$ & $7 / 1,416^{2}$ & $-/ 0.5 \pm 0.4$ & $13 / 1,416^{2}$ & $-/ 0.9 \pm 0.5$ \\
\hline $\begin{array}{c}\text { PCR analysis } \\
\text { (total) }\end{array}$ & $-/ 781$ & 0 & 0 & 0 & 0 \\
\hline
\end{tabular}

${ }^{1}$ examined by pools; ${ }^{2}$ examined individually

inoculating culture medium with the egg material were negative, and none of 370 eggs individually analysed by the PCR method proved to contain Borrelia DNA (Table 1).

A total of 781 unfed larvae hatched from the infected egg masses were tested for the presence of Borrelia DNA either individually or 10, 20, 40, and 50 larvae in a sample. The results were negative in all cases. The same concerns the results of cultivation experiments (Table 2).

The cultures of immobile spiral forms of Bacillus sp., described earlier by Heidrich et al. (1999), were obtained from the eggs of 3 out of 6 females (i.e., 3 out of 6 egg masses used for inoculation) and the larval progenies of 7 out of 15 females. Spirochete-like cells were also found in some microscopic preparations of eggs, and morphologically similar cells, in the preparations of unfed larvae of the daughter generation (Tables 1, 2). Only 1 out of 16 infected females transmitted Borrelia vertically, through the eggs to the larval progeny. However, spirochete-like cells were not detected in fixed smears prepared from the eggs of this female and the larvae hatched from the same egg mass. The infection rate in this progeny was about $7 \%$, and the prevalence of Borrelia in individual larvae was $0.4-0.8$ cells per 100 microscopic fields. Typical Borrelia cells were detected in only about $0.5 \%$ of larvae from the progeny of infected female ticks.

\section{DISCUSSION}

Transovarial transmission of viable Borrelia burgdorferi sensu lato can be confirmed only by inoculating the BSK medium with the test material. In this context, it should be noted that viable Borrelia isolates were obtained, in very rare cases, from unfed Ixodes ricinus larvae collected in North Africa (Younsi et al. 2001), Amblyomma americanum in the United States (Schulze et al. 1986), and Ixodes persulcatus in Russia (Gorelova, unpublished). Single isolates were also derived from the biopsies or blood of laboratory animals used as hosts for I. ricinus larvae collected in natural foci (Stanek et al. 1986, Hammer et al. 2002) or engorged larvae from the progenies of ticks infected in the laboratory (Krampitz 1986). Using dark-field microscopy, live Borrelia were detected in the unfed larvae of the following tick species: Ixodes scapularis (Bosler et al. 1983, Piesman et al. 1986), A. americanum (Schulze et al. 1986), I. ricinus (Hubálek and Halouzka 1998), and $I$. persulcatus (Balashov and Grigor'eva 1997, Balashov et al. 1998). These data are difficult to compare and impossible to evaluate quantitatively.

The results of this study showed that the eggs laid by spontaneously infected female $I$. persulcatus ticks contained the genomic DNA of Borrelia; therefore, the transovarial transmission of Borrelia in these ticks was principally possible. However, the larvae hatched from 
these eggs either contained no Borrelia DNA or its concentration was too low to be detected by our PCR system. This fact may be evidence for the loss of the pathogen in the course of egg development and the hatching of larvae. Typical Borrelia were found in only a few preparations of the larvae hatched from the same egg mass. Of 16 infected female ticks, only the female that laid these eggs was found to transmit Borrelia transovarially to its progeny. The infection rate among these larvae was only $7 \%$, with the prevalence of Borrelia being also very low: $0.4-0.8$ spirochetes per 100 microscopic fields.

Thus, the above data suggest that the transovarial transmission of $B$. burgdorferi sensu lato in the $I$. persulcatus tick - the main vector of this pathogen in Eurasia - is possible, but its probability is very low. This transmission pathway apparently plays no significant role in the maintenance of Borrelia circulation and the dynamics of parameters of infection in adult ticks of the next generation.

There are strong reasons to believe that the functioning of natural foci of ixodid tick-borne borrelioses
(ITBB) in Russia depends primarily on the horizontal and transstadial pathogen transmission, with the determinative effect on the prevalence of infection among unfed adult $I$. persulcatus ticks belonging to the parameters of infection of engorged nymphs. Thus, studies on the long-term dynamics of epizootic activity in natural foci revealed consistent and virtually synchronous changes in the population density and infection rate of adult ticks, on the one hand, and in the abundance of forest voles of the genus Clethrionomys, on the other. The coefficients of correlation between the abundance of these rodents in the previous year and the rate of tick infection by Borrelia in the current year were $r=0.73$ for nymphs and $r=0.84$ for adult ticks. These dynamics of the epizootic activity of natural ITBB foci in the Pre-Ural region eventually determine the long-term dynamics of their epidemic manifestation (Korenberg et al. 2002).

Acknowledgements. This study was supported by a grant from the Russian Foundation for Basic Research, projects nos. 01-04-48127 and 02-04-06349.

\section{REFERENCES}

ADAM T., GRAF B., NEUBERT U., GOBEL U.B. 1992 Detection and classification of Borrelia burgdorferi by direct sequencing of $16 \mathrm{~S}$ rRNA amplified after reverse transcription. Med. Microbiol. Lett. 1: 120-126.

BALASHOV Yu.S., GRIGOR'EVA L.A. 1997: [Localization of Borrelia in the Ixodes persulcatus (Ixodidae) tick.] Dokl. Akad. Nauk 352: 130-132. (In Russian.)

BALASHOV Yu.S., AMOSOVA L.I., GRIGOR'EVA L.A 1998: Transovarial and transphasic transmission of Borrelia by the taiga tick Ixodes persulcatus (Ixodidae). Parazitologiya 32: 489-494. (In Russian.)

BEKLEMISHEV V.N. 1963: [On the assessment of infection prevalence in tick vectors of encephalitis by means of bioassay.] Vopr. Virusol. 2: 240-242. (In Russian.)

BOSLER E.M., COLEMAN J.L., BENACH J.L., MASSEY D.A., HANRAHAN J.P., BURGDORFER W., BARBOUR A.G. 1983: Natural distribution of the Ixodes dammini spirochete. Science 220: 321-322.

DUBININA H.V. 2000: Some peculiarities of the mating behavior in Ixodes persulcatus and Ixodes ricinus ticks (Acarina, Ixodidae): differences in a sexual transmission of the species of Borrelia. Acarina 8: 125-131.

DU YONG, TOU XIYAN, WU XIAOMING, QIEN ZHANG 1990: [Dissemination and transovarial transmission of Borrelia burgdorferi in Ixodes persulcatus (Acari: Ixodidae).] Chin. Vector Biol. Control J. 1: 367-369. (In Chinese.)

GORELOVA N.B., KORENBERG E.I., KOVALEVSKII Yu.V., POSTIC D., BARANTON G. 1996: Isolation of Borrelia from the tick Ixodes trianguliceps (Ixodidae) and the significance of this species in the epizootiology of ixodid tick-borne borrelioses. Parazitologiya 30: 13-18. (In Russian.)
GRIGOR'EVA L.A., TRET'KIAKOV K.A. 1998: Features of the ixodid ticks-Borrelia-small mammals parasitic system in Northwestern Russia. Parazitologiya 32: 422-430. (In Russian.)

HAMMER B., MEINERS T., MARANGONI A., SAMBRI V., GOBEL U.B., HAHL O. 2002: Borrelia burgdorferi sensu lato transmission from tick vector to host: experimental evidence of the involvement of the larval stage Ixodes ricinus. Int. J. Med. Microbiol. 291: 211.

HEIDRICH J., SCHÖNBERG A., STEUBER S., NÖCKLER K., SCHULZE P., VOIGT W.P., SCHEIN E. 1999: Investigation of skin samples from red foxes (Vulpes vulpes) in Eastern Brandenburg (Germany) for the detection of Borrelia burgdorferi s.1. Zentralbl. Bakteriol. 289: 666672.

HUBÁLEK Z., HALOUZKA J. 1998: Prevalence rates of Borrelia burgdorferi sensu lato in host-seeking Ixodes ricinus ticks in Europe. Parasitol. Res. 84: 167-172.

KORENBERG E.I., KOVALEVSKII Yu.V., KARAVANOV A.S., MOSKVITINA G.G. 1999: Mixed infection by tickborne encephalitis virus and Borrelia in ticks. Med. Vet. Entomol. 13: 204-208.

KORENBERG E.I., KOVALEVSKII Yu.V., GORELOVA N.B. 2002: Long-term records of main epizootic parameters in East-European mixed natural foci of tick-borne infections. Int. J. Med. Microbiol. 291: 202.

KRAMPITZ H.E. 1986: In vivo isolation and maintenance of some wild strains of European hard tick spirochetes in mammalian and arthropod. Zentralbl. Bakteriol. Hyg. A 263: $21-28$.

LEVIN M.L., KOVALEVSKY Yu.V., PISKUNOVA A.Yu., SCHEGOLEVA T.V. 1993: Evaluation of the rate of individual tick infection by the Lyme disease agent by 
microscopic analysis of fixed smears. In: E.I. Korenberg (Ed.), Problems of Tick-Borne Borrelioses. Center on Borrelioses for Russia, Moscow, pp. 157-162. (In Russian.)

NAKAO M., MIYAMOTO K. 1992: [Negative finding in detection of transovarial transmission of Borrelia burgdorferi in Japanese ixodid ticks, Ixodes persulcatus and Ixodes ovatus.] Jpn. J. Sanit. Zool. 43: 343-345. (In Japanese.)

NEFEDOVA V.V., KORENBERG E.I., NESTERENKO L.N., GINTSBURG A.L., KOVALEVSKII Yu.V., GORELOVA N.B. 2001: Comparative evaluation of effectiveness of Borrelia indication in ixodid ticks (Ixodidae) by methods of dark-field microscopy and polymerase chain reaction (PCR). Parazitologiya 35: 3-8. (In Russian.)

PIESMAN J., DONAHUE J.G., MATHER T.N., SPIELMAN A. 1986: Transovarially acquired Lyme disease spirochetes (Borrelia burgdorferi) in field-collected larval
Ixodes dammini (Acari: Ixodidae). J. Med. Entomol. 23: 219.

SALINAS-MELENDEZ J.A., TAMEZ-GONZALES R., WELSH-LOZANO O., BARRERA-SALDANA H.A. 1995: Detection of Borrelia burgdorferi DNA in human skin biopsies and dog synovial fluid by the PCR. Rev. Latinoam. Microbiol. 37: 7-10.

SCHULZE T.L., LAKAT M.F., PARKIN W.E., SUISLER J.K., CHARETTE D.J., BOSLER E.M. 1986: Comparison of rates of infection by the Lyme disease spirochete in selected populations of Ixodes dammini and Amblyomma americanum (Acari: Ixodidae). Zentralbl. Bakteriol. Hyg. A 263: 72-78.

STANEK G., BURGER I., HIRSCHEL A., WEWALKA G., RADDA A. 1986: Borrelia transfer by ticks during their life cycle. Zentralbl. Bakteriol. Hyg. A 263: 29-33.

YOUNSI H., POSTIC D., BARANTON G., BOUATTOUR A. 2001: High prevalence of Borrelia lusitaniae in Ixodes ricinus ticks in Tunisia. Eur. J. Epidemiol. 17: 53-56. 